\title{
Factors Influencing the Adoption of COVID-19 Preventive Behaviors in Chile
}

\author{
Nicolás C. Bronfman 1,2,*, Paula B. Repetto ${ }^{2,3}$, Pamela C. Cisternas ${ }^{2,4}$ (D) and Javiera V. Castañeda ${ }^{3}$ \\ 1 Engineering Sciences Department, Universidad Andres Bello, Santiago 7500973, Chile \\ 2 Research Center for Integrated Disaster Risk Management ANID/FONDAP/15110017, \\ Santiago 7820436, Chile; prepetto@uc.cl (P.B.R.); pccisternas@uc.cl (P.C.C.) \\ 3 Department of Psychology, Pontificia Universidad Católica de Chile, Santiago 7820436, Chile; \\ jvcastaneda@uc.cl \\ 4 Industrial and Systems Engineering Department, Pontificia Universidad Católica de Chile, \\ Santiago 7820436, Chile \\ * Correspondence: nbronfman@unab.cl
}

Citation: Bronfman, N.C.; Repetto, P.B.; Cisternas, P.C.; Castañeda, J.V. Factors Influencing the Adoption of COVID-19 Preventive Behaviors in Chile. Sustainability 2021, 13, 5331. https://doi.org/10.3390/su13105331

Academic Editor: John Rennie Short

Received: 12 March 2021

Accepted: 7 May 2021

Published: 11 May 2021

Publisher's Note: MDPI stays neutral with regard to jurisdictional claims in published maps and institutional affiliations.

Copyright: (C) 2021 by the authors Licensee MDPI, Basel, Switzerland. This article is an open access article distributed under the terms and conditions of the Creative Commons Attribution (CC BY) license (https:// creativecommons.org/licenses/by/ $4.0 /)$.

\begin{abstract}
The COVID-19 pandemic forced people worldwide to implement a series of preventive hygiene and distancing measures that have significantly altered their way of life. This study examined an adapted version of the Theory of Planned Behavior (TPB) on adopting preventive behavior against COVID-19. Data was collected using a web survey completed by 1004 college students a few weeks after the first wave of infections in Chile. Our findings show that the subjective norm was the strongest predictor of adopting preventive behaviors, followed by the knowledge level and perceived behavioral control. Contrary to expectations, we found no evidence that an attitude towards preventive action predicted actual adoption of preventive behavior against COVID-19. However, knowledge and social norms play a significant role. We discuss implications for effective risk communication.
\end{abstract}

Keywords: preventive behaviors; theory of planned behavior; subjective norms; COVID-19

\section{Introduction}

The health crisis sparked in 2020 by the SARS-CoV-2 virus causing the COVID-19 pandemic has significantly altered people's lives worldwide and has caused hundreds of millions of confirmed infections and millions of deaths [1]. The pandemic has had a significant economic impact not seen since World War II [2].

Because of the high rate of contagion of the virus, health authorities imposed a series of sanitary measures and restrictions to reduce its spread, which forced the suspension of economic and social activities in many places worldwide. The implementation of these measures revealed that one of the most significant challenges posed by this crisis was encouraging the adoption of preventive behaviors in the population [3-5], particularly among younger adults [6]. Youths are an important group for compliance with preventive behaviors, though their situation involving a low risk of contracting serious symptoms as a result of COVID-19 [7] and the high mental health impacts they could face due to the interruption of their social and academic life [8-10] discourages their adherence to sanitary measures. Consequently, they are an important vector of contagion [11,12].

Due to the particular aforementioned situation for young people during the pandemic, it is essential to know the psychosocial factors that influence the adoption of preventive measures for this group and identify the differences with the factors that motivate the adoption of preventive measures in the general population. Consequently, this study aimed to investigate the influence of several predictive variables on the adoption of preventive behavior by university students against COVID-19 in Chile. To contribute to knowledge about preventive behaviors against COVID-19, this study assessed the effect of attitudes, 
subjective norms, and perceived behavioral control on adopting preventive behaviors. In addition, knowledge about COVID-19 was incorporated as a behavior predictor since, as a new hazard, it can be a determining factor in people's behavior [13-15].

\subsection{Theory of Planned Behavior (TPB)}

Several theoretical models have been used to understand the adoption of preventive behaviors in response to health problems. The Theory of Planned Behavior (TPB) is widely used to explain these behaviors [16-25]. TPB is an extension of the Theory of Reasoned Action (TRA) [26] and postulates that the direct predictor of behavior is the behavioral intention, which in turn is explained by three components: attitudes, subjective norms, and perceived behavioral control [27]. In this model, attitudes refer to each person's evaluation of a behavior based on their beliefs about the particular behavior's characteristics, probable outcomes associated with it, and whether it is favorable or unfavorable. Subjective norms correspond to each individual's beliefs about whether their reference groups approve or disapprove of the behavior and whether they are motivated to comply with their reference group's norms $[27,28]$. Perceived behavioral control refers to the person's perceived power to perform a behavior, considering the beliefs about his or her ability to perform it [28].

In this model, the authors propose that a favorable attitude, combined with the approval of the behavior by others close to them and a positive perception of control, strengthens the intention to perform that particular behavior [26]. Theoretically, the three components of the theory have independent effects on behavioral intention [26,27]: attitudes and subjective norms directly affect behavioral intention. In contrast, perceived control affects behavioral intention and preventive behavior $[29,30]$. While the results of studies using the TPB are diverse, attitude is generally recognized as the best predictor of behavioral intention, as is the perception of control. Subjective norms appear to have a more limited effect on intention $[16,31]$. Nevertheless, other studies have noted that the strength of the effect of attitude, subjective norms, and perception of control varies according to the behavior to which they are applied $[17,26,29]$.

\subsection{TPB and Preventive Behaviors in Pandemic}

The study by Cheng and $\mathrm{Ng}$ [19] was one of the few to use the TPB to examine the factors influencing preventive behavior during an epidemic, particularly the Severe Acute Respiratory Syndrome (SARS) epidemic between 2002 and 2004. They concluded that the subjective norm was the strongest predictor of the intention and adoption of preventive behaviors. The knowledge level about the virus also had a significant effect on behavioral intention [19].

More recently, Barile et al. [32] integrated the Health Belief Model (HBM) and the TPB to explore both barriers and facilitators for public use of face coverings to prevent the contagion and spread of the SARS-CoV-2 virus. They found that perceived subjective norms, self-efficacy, and attitudes were positively associated with an intention to wear a face-covering in public [32]. In another study which aimed to determine the main predictors of actual social distancing behavior to prevent the spread of the SARS-CoV-2 virus, Das et al. [33] found that perceived behavioral control was the most robust predictor on both intentions and actual social distancing behavior in Bangladesh. They also found that subjective norms were also significant. Similarly, in a study to investigate the influence of the several predictive factors on the intention to adopt preventive behaviors against COVID-19 in China, Ahmad et al. [13] developed a behavioral framework composed of TRA and TPB, and incorporated a set of additional factors (risk perception, epidemic knowledge, and risk aversion, among others). They found that governments' guidelines on epidemic prevention, risk perception, epidemic knowledge, perceived behavioral control, and subjective norms were the most important and influential factors on individuals' intention. The attitudes towards prevention exhibited a lower influence [13]. These findings suggest that other variables play a relevant role and should be considered to understand these behaviors, particularly among groups that appear to adhere less to these behaviors. 


\section{Overview of the Present Study}

In this study, we used an adapted version of TPB to characterize the adoption of preventive behaviors and determine the factors with the most significant predictive power. We focused on behaviors that were already present and prescribed for the population. Consequently, we did not measure future intention. Previous studies have made similar adjustments that have faced the same difficulty $[34,35]$. Thus, we hypothesized that attitudes (H1), subjective norms (H2), and perceived behavioral control (H3) have a significant and positive effect on COVID-19 preventive behavior. Also, we evaluated knowledge about COVID-19 and we hypothesized that the knowledge level about COVID-19 has a significant and positive effect on adopting preventive behaviors $(\mathrm{H} 4)$.

\section{Materials and Methods}

\subsection{Materials}

Data were obtained from a web-based survey aimed to assess preventive behaviors against the COVID-19 pandemic developed by the research team. The survey was organized into 10 sections. We used five for the purposes of this study. Section 1 measured preventive behaviors in three dimensions: social distancing, hygiene, and information seeking. Section 2 contained questions associated with attitudes to preventive measures. Section 3 measured subjective norms and perceived behavioral control. Section 4 addressed knowledge questions related to myths and realities about COVID-19. Finally, the last one included sociodemographic questions to characterize the respondents. Each of the TPB latent variables was constructed based on a set of items used in previous studies $[16,17,19,29,36]$. The items used to build the latent variables of the model are described in detail below.

Attitude. Measured through two concepts: perceived benefits ( 3 items) and barriers ( 3 items). Participants had to respond to the six items on a five-point Likert scale, from (1) "very unlikely" to (5) "very likely" (see Table 1).

Table 1. Mean values and standard deviation $(S D)$ for each item measuring attitude, subjective norms, and perceived behavioral control.

\begin{tabular}{|c|c|c|c|}
\hline \multirow{2}{*}{\multicolumn{2}{|c|}{$\begin{array}{c}\text { Item Description } \\
\text { Attitude }^{1}\end{array}$}} & \multicolumn{2}{|c|}{$\begin{array}{l}\text { All Sample } \\
(n=1004)\end{array}$} \\
\hline & & Mean & $(S D)$ \\
\hline \multicolumn{4}{|c|}{ Benefits $(\alpha=0.84)$} \\
\hline Be1 & $\begin{array}{l}\text { If I adopt these measures, how likely am I to contract the } \\
\text { coronavirus (COVID-19)? }\end{array}$ & 2.25 & $(0.93)$ \\
\hline $\mathrm{Be} 2$ & $\begin{array}{l}\text { If I adopt these measures, how likely am I to infect others with } \\
\text { the coronavirus (COVID-19)? }\end{array}$ & 2.09 & $(0.91)$ \\
\hline $\mathrm{Be}^{\bullet}$ & $\begin{array}{l}\text { If I adopt these measures, I will be less anxious about } \\
\text { contracting the coronavirus (COVID-19). }\end{array}$ & 2.64 & $(1.35)$ \\
\hline \multicolumn{4}{|c|}{ Barriers $(\alpha=0.67)$} \\
\hline Ba1 & $\begin{array}{l}\text { If I adopt these measures, they will cause me } \\
\text { considerable inconvenience. }\end{array}$ & 1.96 & $(1.12)$ \\
\hline $\mathrm{Ba} 2$ & $\begin{array}{c}\text { If I adopt these measures, they will greatly change my } \\
\text { daily routines. }\end{array}$ & 2.92 & $(1.39)$ \\
\hline Ва3 & $\begin{array}{l}\text { If I adopt these measures, I will take longer to perform some } \\
\text { activities (e.g., preparing food, studying, etc.). }\end{array}$ & 2.78 & $(1.41)$ \\
\hline \multicolumn{4}{|c|}{ Subjective Norms ${ }^{2}$} \\
\hline \multicolumn{4}{|c|}{ Normative beliefs $(\alpha=0.81)$} \\
\hline NB1 & $\begin{array}{l}\text { My family thinks I should adopt the measures to prevent the } \\
\text { coronavirus (COVID-19). }\end{array}$ & 4.68 & $(0.70)$ \\
\hline NB2 & $\begin{array}{l}\text { My best friends think I should adopt the measures to prevent } \\
\text { the coronavirus (COVID-19). }\end{array}$ & 4.36 & $(0.85)$ \\
\hline
\end{tabular}


Table 1. Cont.

\begin{tabular}{|c|c|c|c|}
\hline \multicolumn{2}{|r|}{ Item Description } & \multicolumn{2}{|c|}{$\begin{array}{l}\text { All Sample } \\
(n=1004)\end{array}$} \\
\hline NB3 & $\begin{array}{c}\text { My colleagues think I should adopt the measures to prevent } \\
\text { the coronavirus (COVID-19). }\end{array}$ & 4.31 & $(0.87)$ \\
\hline NB4 & $\begin{array}{l}\text { My teacher(s) thinks I should adopt the measures to prevent } \\
\text { the coronavirus (COVID-19). }\end{array}$ & 4.58 & $(0.74)$ \\
\hline \multicolumn{4}{|c|}{ Motivation to comply $(\alpha=0.89)$} \\
\hline $\mathrm{MC1}$ & $\begin{array}{l}\text { What my family thinks motivates me to adopt coronavirus } \\
\text { prevention measures (COVID-19). }\end{array}$ & 4.13 & $(1.09)$ \\
\hline MC2 & $\begin{array}{l}\text { What my best friends think motivates me to adopt coronavirus } \\
\text { prevention measures (COVID-19). }\end{array}$ & 3.75 & $(1.16)$ \\
\hline MC3 & $\begin{array}{l}\text { What my colleagues think motivates me to adopt coronavirus } \\
\text { prevention measures (COVID-19). }\end{array}$ & 3.57 & $(1.12)$ \\
\hline $\mathrm{MC} 4$ & $\begin{array}{l}\text { What my teacher(s) thinks motivates me to adopt coronavirus } \\
\text { prevention measures (COVID-19). }\end{array}$ & 3.87 & $(1.14)$ \\
\hline \multicolumn{4}{|c|}{ Perceived Behavioral Control $^{2}(\alpha=0.52)$} \\
\hline PBC1 & $\begin{array}{l}\text { If I want to, I can adopt coronavirus prevention measures } \\
\text { (COVID-19). }\end{array}$ & 4.51 & $(0.98)$ \\
\hline PBC2 & $\begin{array}{l}\text { I am confident that I am able to implement coronavirus } \\
\text { prevention measures (COVID-19). }\end{array}$ & 4.67 & $(0.66)$ \\
\hline PBC3 & $\begin{array}{l}\text { I find it difficult to implement coronavirus prevention } \\
\text { measures (COVID-19). }\end{array}$ & 4.05 & $(1.14)$ \\
\hline
\end{tabular}

Mean values and standard deviations (SD) for each item. Cronbach's Alpha of each predictor variable included in the model $(\alpha)$ was incorporated. ${ }^{1}$ Items were rated on a 5-point Likert scale, from [1] very unlikely to [2] very likely. ${ }^{2}$ Items were assessed on a 5 -point Likert scale, from [1] strongly disagree to [2] strongly agree. $\bullet^{\bullet}$ item removed from the model.

Subjective norm. This was measured through four normative belief items and four compliance motivation items (see Table 1). The following significant groups were included: family, best friends, peers, and teachers. Higher education teachers were incorporated as a reference group, since college students in previous interviews mentioned them. Participants had to respond on a five-point Likert scale, from (1) "strongly disagree" to (5) "strongly agree".

Perceived behavioral control. We used three items to which participants had to respond through a five-point Likert scale, from (1) "strongly disagree" to (5) "strongly agree" (see Table 1), and that correspond to the three type of behaviors included: social distancing, hygiene, and information seeking.

Knowledge of COVID-19. To assess knowledge, we developed 11 items based on the study by Cheng and $\mathrm{Ng}$ [19]. Five items were assertions related to myths associated with COVID-19 (items K3, K6, K7, K9, and K10 in Table 2), and six were assertions of fundamental knowledge of COVID-19 (items K1, K2, K4, K5, K8, and K11 in Table 2). Respondents had to answer whether each statement was (1) "true", (2) "false", or (3) "I do not know". The items associated with myths were recoded to (0) true, and I do not know, (1) false, while items related to fundamental knowledge were recoded to (1) true, (0) false, and I do not know. 
Table 2. Percentage of correct answers for each item of knowledge about COVID-19.

\begin{tabular}{|c|c|c|}
\hline \multicolumn{2}{|r|}{ Item Description } & $\begin{array}{l}\text { All Sample } \\
(n=1004)\end{array}$ \\
\hline \multicolumn{2}{|r|}{ Knowledge $(\alpha=0.54)$} & $(\%)$ \\
\hline $\mathrm{K} 1^{\bullet}$ & Fever is one of the main symptoms of the coronavirus. & 83.1 \\
\hline $\mathrm{K} 2^{\bullet}$ & $\begin{array}{l}\text { Young people like me cannot get sick from the coronavirus } \\
\text { (COVID-19). }\end{array}$ & 98.5 \\
\hline K3 & $\begin{array}{l}\text { Drinking alcohol prevents the spread of the coronavirus } \\
\text { (COVID-19). }\end{array}$ & 93.8 \\
\hline $\mathrm{K} 4$ & There is still no vaccine to prevent the coronavirus. & 78.0 \\
\hline $\mathrm{K} 5^{\bullet}$ & $\begin{array}{c}\text { Asymptomatic people infected with the coronavirus (COVID-19) } \\
\text { cannot infect others. }\end{array}$ & 97.5 \\
\hline K6 & $\begin{array}{l}\text { Vitamin C prevents the transmission of the coronavirus } \\
\text { (COVID-19). }\end{array}$ & 67.8 \\
\hline K7 & $\begin{array}{l}\text { Exposure to the sun or to temperatures above } 25^{\circ} \mathrm{C} \text { prevents the } \\
\text { spread of the coronavirus (COVID-19). }\end{array}$ & 74.7 \\
\hline $\mathrm{K} 8^{\bullet}$ & The incubation period of the virus can be 14 days. & 86.3 \\
\hline K9 & The coronavirus can be transmitted through mosquito bites. & 61.5 \\
\hline $\mathrm{K} 10^{\bullet}$ & $\begin{array}{l}\text { The exchange of banknotes and coins CANNOT transmit } \\
\text { COVID-19. }\end{array}$ & 81.9 \\
\hline K11 & The best protection against the coronavirus is physical distancing. & 85.4 \\
\hline
\end{tabular}

Preventive behaviors. Fourteen items were developed based on three behavioral dimensions: social distancing behavior ( 4 items), hygiene ( 7 items), and information seeking (3 items) (see Table 3). Participants had to respond on a frequency scale: (1) "never", (2) "rarely", (3) "sometimes", (4) "very often", (5) "always", and (6) "I do not know".

Table 3. Mean values and standard deviation $(S D)$ for each item measuring preventive behaviors against COVID-19.

\begin{tabular}{|c|c|c|c|}
\hline \multirow{2}{*}{\multicolumn{2}{|c|}{$\begin{array}{c}\text { Item Description } \\
\text { Social distancing Behavior }(\alpha=0.67)\end{array}$}} & \multicolumn{2}{|c|}{$\begin{array}{l}\text { All sample } \\
(n=1004)\end{array}$} \\
\hline & & \multirow{2}{*}{ Mean } & \multirow{2}{*}{ SD } \\
\hline LB1 & $\begin{array}{l}\text { During this period, I avoided leaving my home and being in } \\
\text { contact with other people. }\end{array}$ & & \\
\hline LB2 & $\begin{array}{l}\text { During this period, I avoided going out to shop if I could do } \\
\text { it online. }\end{array}$ & 4.41 & $(0.98)$ \\
\hline LB3 & $\begin{array}{l}\text { When I left home, I did so using the individual temporary } \\
\text { permits for essential activities (requested at } \\
\text { www.comisariavirtual.cl). }\end{array}$ & 4.75 & $(0.69)$ \\
\hline LB4 & $\begin{array}{l}\text { I avoided visits and holding or participating in social events } \\
\text { such as parties and gatherings. }\end{array}$ & 4.84 & $(0.57)$ \\
\hline \multicolumn{4}{|c|}{ Hygiene Behavior $(\alpha=0.69)$} \\
\hline HB1 & $\begin{array}{l}\text { I wore a face mask on the street and in closed places } \\
\text { (supermarket, pharmacy, etc.). }\end{array}$ & 4.96 & $(0.27)$ \\
\hline HB2 & I disinfected purchased products with bleach or disinfectant. & 4.11 & $(1.20)$ \\
\hline HB3 & $\begin{array}{l}\text { I washed my hands when I got home with an alcohol-based } \\
\text { hand sanitizer or soap and water. }\end{array}$ & 4.86 & $(0.48)$ \\
\hline HB4 & $\begin{array}{l}\text { I changed clothes immediately upon arriving home after } \\
\text { going out. }\end{array}$ & 3.48 & $(1.36)$ \\
\hline HB5 & $\begin{array}{l}\text { I washed my hands with an alcohol-based hand sanitizer after } \\
\text { sneezing, coughing, or wiping my nose. }\end{array}$ & 4.13 & $(1.10)$ \\
\hline HB6 & $\begin{array}{l}\text { When I left my home, I avoided hugging, shaking hands, or } \\
\text { kissing on the cheek when greeting another person. }\end{array}$ & 4.71 & $(0.63)$ \\
\hline HB7 & $\begin{array}{l}\text { When I left my home, I tried to keep at least one meter of } \\
\text { distance from other people. }\end{array}$ & 4.71 & $(0.58)$ \\
\hline
\end{tabular}


Table 3. Cont.

\begin{tabular}{|c|c|c|c|}
\hline & Item Description & \multicolumn{2}{|c|}{$\begin{array}{l}\text { All sample } \\
(n=1004)\end{array}$} \\
\hline \multicolumn{2}{|r|}{ Information-seeking Behavior $(\alpha=0.72)$} & & \\
\hline ISB1 & $\begin{array}{l}\text { I was aware of the sanitary or isolation restrictions of the } \\
\text { territory where I live (mandatory quarantine, cordon sanitaire, } \\
\text { curfew, etc.). }\end{array}$ & 4.70 & $(0.67)$ \\
\hline ISB2 & $\begin{array}{c}\text { I was regularly informed of the national evolution of } \\
\text { the pandemic. }\end{array}$ & 4.04 & $(1.04)$ \\
\hline ISB3 & $\begin{array}{c}\text { I looked for updated information on the figures provided by the } \\
\text { Ministry of Health. }\end{array}$ & 3.47 & $(1.29)$ \\
\hline
\end{tabular}

Mean values and standard deviations (SD) for each item. Cronbach's Alpha of each behavior variable included in the model $(\alpha)$ was incorporated. Items were rated on the following frequency scale: [1] never, [2] rarely, [3] sometimes, [4] very often, and [5] always.

\subsection{Procedure and Participants}

The questionnaire was initially validated by the research team and the opinion of experts, to later be evaluated and validated in a focus group with 9 college students (five women) between 18 and 23 years old from various universities located in Santiago, Chile. The information obtained allowed the items to be adjusted and validated.

In Chile, the first confirmed case of COVID-19 was reported on 3 March 2020, almost two months after the WHO declared a health emergency. Due to the rapid spread of the virus, two weeks after the first confirmed case, the Chilean government declared a state of emergency, and closed the borders. The peak of confirmed infections during the first wave in Chile occurred between May and June 2020.

We studied preventive behaviors after the first contagion peak, using a web survey administered to undergraduate and graduate students at Universidad Andrés Bello between 24 August and 8 November 2020. One thousand and four students successfully completed the survey: $67.3 \%$ female, mean age 25.7 years old (SD = 7 years; range 18 to 50 years old), and $82.1 \%$ single. The average response time was $20 \mathrm{~min}$.

At the beginning of the survey, all respondents were informed about their participation conditions and voluntarily agreed to participate in the study by signing an informed consent form. The Ethics Committee approved all procedures of the Universidad Andrés Bello.

\subsection{Data Analysis}

First, we conducted descriptive analyses to examine all items and measures included. Then, we used Cronbach's alpha coefficient ( $\alpha$-Cronbach) to evaluate the internal reliability of the scales, Kline [37] suggests values above 0.7 for highly consistent scales, and that values close to 0.6 are acceptable [38]. However, in analyses with latent variables, values lower than 0.7 are acceptable if the sample size is large enough to estimate all the model parameters $[30,37]$. Finally, a structural equations model was used to test the hypotheses of the study.

Structural Equation Model. We used the software IBM SPSS AMOS 26.0 to analyze the proposed structural equation model. We replaced missing values for each variable with the mean (the non-stochastic imputation method). The model fit was evaluated through the chi-squared $\left(x^{2}\right)$ indices, robustness of mean square error approximation (RMSEA), and comparative fix index (CFI) [39]. Finally, the proportion of variance explained by the model was measured using the Squared Multiple Correlation $\left(R^{2} S M C\right)$.

Model variables were entered as follows (see Figure 1). Attitude comprised the average of the benefits items and the average of the barrier items. The subjective norm was constructed using the average of the four normative belief items and the four items of motivation to comply. The three items that comprised the perceived behavioral control were entered as observed variables. The knowledge level about COVID-19 was included in the model using the score for each of the calculated factors. Finally, the adoption of preventive 
behaviors consisted of the average of each behavioral dimension: social distancing behavior, hygiene, and information seeking.

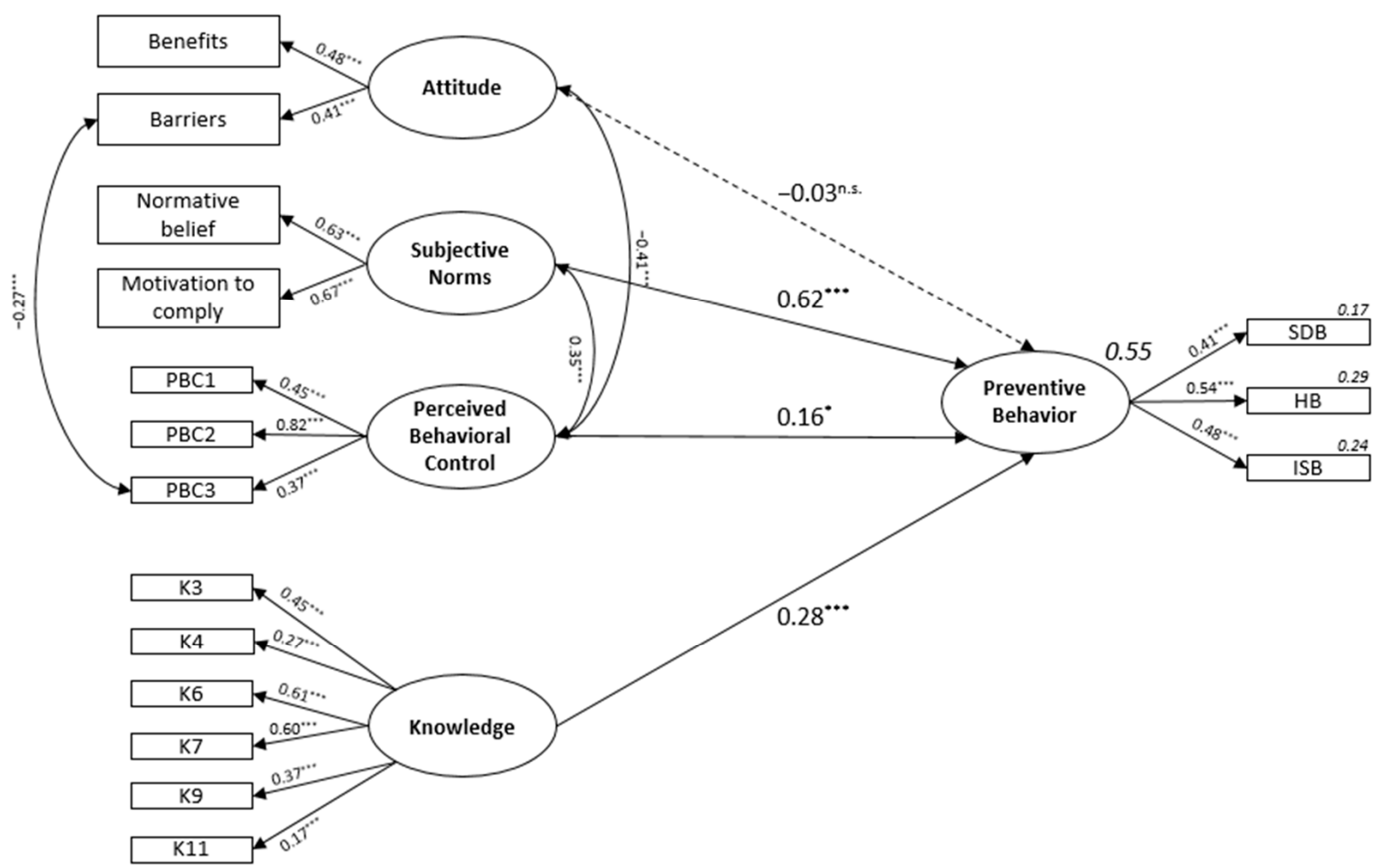

Figure 1. General model of COVID-19 preventive behavior. Two-headed arrows indicate the covariances suggested by the analysis to improve the fit of the model. Arrows depicted the direct relationships between constructs, and the values above them are the standardized regression coefficients that represent their strength. Dotted lines indicate non-significant coefficients. The values in cursive represent the proportion of explained variance of COVID-19 preventive behavior. SDB: Social distancing behavior, HB: Hygiene behavior, and ISB: Information-seeking behavior. ${ }^{* *} p<0.001$; $^{* *} p<0.05$; ${ }^{*} p<0.1$; n.s. non-significant at $p$-value $(p>0.05)$.

\section{Results}

\subsection{Internal Consistency Analysis}

An internal consistency analysis through Cronbach's alpha for each latent variable was developed.

Attitude. Before calculating internal reliability, the Be3 benefits item (see Table 1) was inverted, so the score was in the same direction as the remaining two items. The three benefit items' internal reliability (Be1, Be2, and Be3) was $\alpha=0.45$. After the inverted item Be3 was eliminated, the reliability of the scale rose to $\alpha=0.84$. The reliability of the barriers scale (items Ba1, Ba2, and Ba3) was $\alpha=0.67$.

Subjective norm. The internal reliability of the four normative belief items (NB1, NB2, NB3, and NB4) was $\alpha=0.81$, while for the four compliance motivation items (MC1, MC2, MC3, and MC4), it was $\alpha=0.89$ (see Table 1).

Perceived behavioral control. Item $\mathrm{PBC} 3$ was inverted so that it went in the same direction as the remaining items. Considering the three items ( $\mathrm{PBC} 1, \mathrm{PBC} 2$, and $\mathrm{PBC} 3)$, the internal reliability of this scale was $\alpha=0.52$ (see Table 1 ).

Knowledge. The internal reliability of the 11 knowledge items was $\alpha=0.46$. We eliminated the five items with the lowest item-to-total correlation to improve the scale's reliability, increasing it to $\alpha=0.54$ (see Table 2).

Preventive behavior. The internal reliability of the social distancing, hygiene, and information-seeking scales was $\alpha=0.67, \alpha=0.69$, and $\alpha=0.72$, respectively (see Table 3). 


\subsection{TPB Model}

The initial general model did not have a good fit (see Table 4). Three covariances were suggested by the modification indices, these were: between perceived behavioral control and subjective norm, between perceived behavioral control and attitude, and finally between the average of the perceived barriers (attitude) and the $\mathrm{PBC} 3$ item of perceived behavioral control. The incorporation of covariance between the TPB latent variables is reasonable because, although the variables are conceptually independent, empirically, they are free to correlate with each other [30]. Incorporating the third covariance is explained by the fact that the items are related to perceived barriers to performing preventive behaviors regarding COVID-19. Once we performed the adjustments to the model, the overall fit improved and reached the fit criteria' satisfactory values (see Table 4). The results of the Final General Model are shown in Figure 1.

Table 4. Fit Indexes for the Structural Models.

\begin{tabular}{ccccccc}
\hline & $x^{2}$ & $d f$ & CFI & RMSEA & CI90\% ${ }_{\text {RMSEA }}$ & $\Delta d f$ \\
\hline Initial General Model $(n=1004)$ & 411.52 & 100 & 0.80 & 0.056 & {$[0.050-0.061]$} & \\
Final General Model $(n=1004)$ & 233.94 & 97 & 0.91 & 0.038 & {$[0.031-0.044]$} & 3 \\
\hline
\end{tabular}

Fit criteria: Accepted values for the adjustment indices are based on Hair et al. (2010). The RMSEA should be less than 0.05 for a good fit, but values close to 0.1 are acceptable, as they indicate a moderate fit of the model to the data. For the CFI, values greater than 0.95 indicate an excellent fit, although values of up to 0.8 are acceptable. $\Delta d f$ difference on degrees of freedom regarding the initial general model.

The proposed model explains 55\% of the variance of preventive behavior adoption against COVID-19. Only the subjective norm, perceived behavioral control, and knowledge predictors obtained statistically significant coefficients, confirming $\mathrm{H} 2, \mathrm{H} 3$, and $\mathrm{H} 4$ and rejecting H1. Based on the value of the standardized coefficients (see Figure 1), the subjective norm was the strongest predictor of the behaviors studied. Finally, based on the mean values of the items that comprise the subjective norm reported in Table 1, family members and teachers would be the greatest motivators for adopting preventive measures.

\section{Discussion}

This study's main objective was to examine the influence of several predictor variables on adopting COVID-19 preventive behaviors in Chile, based on a solid theoretical framework such as TPB. Our findings indicate that the subjective norm is the strongest predictor of adopting preventive behaviors, followed by the knowledge level and the perceived behavioral control. Contrary to expectations, attitudes had no statistically significant influence on the adoption of preventive behaviors.

\subsection{Subjective Norm}

In line with previous studies $[13,19,32,33]$, the subjective norm was positively and significantly related to adopting preventive behaviors. Compared to the other predictors included in the study, subjective norms had the highest predictive power on adopting hygiene, social distancing, and information-seeking behaviors to prevent the transmission and spread of the SARS-CoV-2 virus. Subjective norms reflect the individual's general observation of whether important reference groups (family, friends, teachers) accept, encourage, and perform the preventive behaviors during the crisis [33]. Then, in the context of the COVID-19 situation, social pressures from significant others on adopting preventive behaviors would be the primary motivator for adopting preventive hygiene and social distancing behaviors in Chile. These results are consistent with previous research that emphasizes the role of social norms in the adoption of these behaviors [40-43]. It is important to understand that interaction between different groups is not only essential for the adoption of preventive behaviors but also for strengthening community resilience [5].

Given our sample's characteristics (undergraduate and graduate students), our results suggest that higher education professors emerge as one of the reference groups that can 
stimulate students to adopt COVID-19 preventive behaviors. This is likely because social distancing restrictions and voluntary or mandatory isolation has been imposed since March 2020 by Chile's health authority, and most higher education students had to remain at home during the first months of the pandemic, carrying out their learning activities online. Thus, university students' most significant interactions in the early months of the pandemic were with their family members and professors.

\subsection{Knowledge}

The knowledge level is not commonly included as a predictive variable in TPB. However, since COVID-19 poses a new hazard to people's health, we believe that the knowledge level about COVID-19 should significantly influence preventive behavior adoption and our results supported this hypothesis. The knowledge level about COVID-19 was positively and significantly related to adopting preventive behaviors: the higher the knowledge level, the higher the actual adoption of preventive actions against COVID-19. This result confirms reports in previous studies indicating that knowledge is relevant in contexts of high uncertainty such as a pandemic [13-15,19]. In light of this result, we conclude that risk communication strategies implemented to counter COVID-19 require sharing knowledge and addressing the gaps they may find to be more effective. In fact, the TPB proposes that individuals assess each behavior. This assessment may be influenced by the knowledge they have about how useful or not this behavior might be, and therefore, this knowledge may influence attitudes. These findings are consistent with what West and colleagues $[44,45]$ have argued about the need to implement interventions that recognize the need for people to understand how behaviors reduce the risk of being infected and that are associated with how the virus is transmitted.

\subsection{Perceived Behavioral Control}

The more people feel that they have the resources and skills necessary to perform and maintain preventive behavior, the more likely they are to adopt the behavior [27]. Our results show that perceived behavioral control had a positive and significant impact on the actual adoption of COVID-19 preventive behaviors, suggesting that study participants believe they can adopt measures to avoid infection and prevent the spread of the virus. This result agrees with that reported in previous studies, which reinforce the importance of perceived behavioral control over the final adoption of prevent behaviors $[13,32,33,41]$. Consequently, it is necessary that communication strategies reinforce the idea that people have the necessary skills to adopt preventive measures that protect them and their families against COVID-19.

\subsection{Attitude}

In general terms, studies based on TPB show that the predictive power of attitude on the adoption of preventive behaviors varies according to the behavior being studied $[17,26,29]$. Our research found no evidence that attitudes toward the preventive behaviors were associated with the actual adoption of these behaviors. This result is supported by recent studies related to preventive behaviors against COVID-19, in which attitudes had the least predictive power over the adoption of preventive behaviors [13,33,41]. It is likely that since this is a new hazard, there is considerable ambiguity about the real pros and cons of adopting preventive behaviors; therefore, other predictor variables such as subjective norms and knowledge of a pandemic or epidemic acquire greater significance because they facilitate individual decisions to adopt preventive behaviors. In line with our assumption, Cheng and Ng [19] also found that attitude had the least predictive power on the adoption of preventive behaviors in the SARS epidemic (2002-2004 epidemic), and argue that subjective norms are more relevant when the context or the behavior under study is ambiguous [19]. 


\subsection{Implications}

The results reported in our study have important implications for those responsible for designing programs, plans, and strategies to encourage the adoption of preventive behaviors in the face of an epidemic such as COVID-19. In light of the significant predictive power of the subjective norm on the adoption of preventive behaviors in front of COVID-19, the formulators of preventive programs (local governments, health institutions, educational establishments, etc.) should strategically consider the participation of reference groups as the main driving and motivating agents for the adoption of preventive behaviors. It is particularly worth noting the role that higher education teachers can play in implementing programs and strategies to encourage preventive behaviors in young adults in the face of a new epidemic outbreak. Higher education teachers are potential motivators for their students to adopt preventive behaviors and objectively represent a practical, direct, and permanent communication channel with young people.

The effectiveness of the communication strategies implemented by local governments and other preventive program formulators is a key element in combating the COVID-19 pandemic [46-49]. As this is a new hazard, people need accurate, reliable, and timely information to adopt effective preventive behaviors [46]. Our results are consistent with this premise in that the knowledge level about COVID-19 was positively and significantly related to the actual adoption of preventive behaviors. In light of this result, the more influential the future communication strategies associated with COVID-19, the more active and effective the adoption of preventive behaviors will be in the population.

Finally, perceived behavioral control was positively and significantly related to the adoption of preventive behaviors. Also, our results show that participants report having the necessary resources and skills to perform and maintain the preventive behaviors associated with hygiene and social distancing. Under this favorable scenario, formulators of preventive programs should focus on strengthening and preserving people's heightened sense of behavioral control, for example, by reinforcing the benefits of performing the behavior.

\section{Conclusions}

The study on the adoption of preventive behaviors to cope with the COVID-19 epidemic is new in the health sector, and to date, there are more questions than answers. Based on a solid theoretical framework such as TPB, we conclude that subjective norms represent the main predictor of the adoption of preventive behaviors in the face of COVID19 , followed by the knowledge level and perceived behavioral control. We also conclude that, since this is a new hazard where there is considerable ambiguity about the real pros and cons of adopting preventive behaviors, the attitude toward preventive behaviors decreases its predictive power on adopting preventive behaviors, probably when knowledge is limited.

Certain limitations in this study are worth mentioning. First, our study used crosssectional data, which prevented us from generalizing our results and the inference causality. Future research should use longitudinal data for more robust results. Second, given that our sample consisted of undergraduate and graduate university students, we should be cautious about extending these results to other specific groups that are unlikely to possess the same level of knowledge. The model used could better predict the adoption of preventive behaviors and provide more comprehensive results if future research could include other population groups and obtain reliability coefficients over the 0.7 value for all the latent variables of the model. Finally, despite the studies' self-reporting nature, participants overall reported high compliance about these behaviors, while findings from other studies, such as the COVID-19 Social Study, also indicate that overall compliance with behaviors is high [50]. 
Author Contributions: Conceptualization, N.C.B., P.B.R., P.C.C. and J.V.C.; Formal analysis, N.C.B. and P.C.C.; Funding acquisition, N.C.B. and P.B.R.; Investigation, N.C.B., P.B.R., P.C.C. and J.V.C.; Methodology, N.C.B., P.B.R., P.C.C. and J.V.C.; Project administration, N.C.B.; Resources, N.C.B.; Software, P.C.C.; Supervision, N.C.B.; Validation, N.C.B., P.B.R. and P.C.C.; Visualization, P.C.C.; Writing-original draft, P.C.C. and J.V.C.; Writing-review \& editing, N.C.B., P.B.R., P.C.C. and J.V.C. All authors have read and agreed to the published version of the manuscript.

Funding: This research was partially funded by the National Agency of Research and Development of Chile (ANID) of the Ministry of Science, Technology, Knowledge and Innovation of Chile through the National Fund for Scientific and Technological Research (grant no. ID1180996/FONDECYT/ANID) and by the Research Center for Integrated Disaster Risk Management (CIGIDEN), (grant no. ANID/ FONDAP / 15110017).

Institutional Review Board Statement: The study was approved by the Institutional Ethics Committee of Universidad Andres Bello (023 12 August 2020).

Informed Consent Statement: Informed consent was obtained from all subjects involved in the study.

Data Availability Statement: The data presented in this study are available upon request from the corresponding author. Data is not publicly available due to confidentiality agreement with participants.

Conflicts of Interest: The authors declare no conflict of interest.

\section{References}

1. World Health Organization. Coronavirus Disease (COVID-19) Dashboard. Available online: https://covid19.who.int/ (accessed on 15 February 2021).

2. World Bank. COVID-19 to Plunge Global Economy into Worst Recession since World War II. Available online: https: //www.worldbank.org/en/news/press-release/2020/06/08/covid-19-to-plunge-global-economy-into-worst-recession-sinc e-world-war-ii (accessed on 30 March 2021).

3. Betsch, C. How behavioural science data helps mitigate the COVID-19 crisis. Nat. Hum. Behav. 2020, 4, 438. [CrossRef]

4. Van Bavel, J.J.; Baicker, K.; Boggio, P.S.; Capraro, V.; Cichocka, A.; Cikara, M.; Crockett, M.J.; Crum, A.J.; Douglas, K.M.; Druckman, J.N. Using social and behavioural science to support COVID-19 pandemic response. Nat. Hum. Behav. 2020, 4, 460-471. [CrossRef]

5. Drury, J.; Carter, H.; Ntontis, E.; Guven, S.T. Public behaviour in response to the COVID-19 pandemic: Understanding the role of group processes. BJPsych Open 2021, 7, e11. [CrossRef]

6. Nivette, A.; Ribeaud, D.; Murray, A.; Steinhoff, A.; Bechtiger, L.; Hepp, U.; Shanahan, L.; Eisner, M. Non-compliance with COVID-19-related public health measures among young adults in Switzerland: Insights from a longitudinal cohort study. Soc. Sci. Med. 2021, 268, 113370. [CrossRef] [PubMed]

7. Snape, M.D.; Viner, R.M. COVID-19 in children and young people. Science 2020, 370, 286-288. [CrossRef]

8. Capone, V.; Caso, D.; Donizzetti, A.R.; Procentese, F. University student mental well-being during COVID-19 outbreak: What are the relationships between information seeking, perceived risk and personal resources related to the academic context? Sustainability 2020, 12, 7039. [CrossRef]

9. O'Reilly, A.; Tibbs, M.; Booth, A.; Doyle, E.; McKeague, B.; Moore, J. A rapid review investigating the potential impact of a pandemic on the mental health of young people aged 12-25 years. Ir. J. Psychol. Med. 2020, 1-16. [CrossRef] [PubMed]

10. Xiong, J.; Lipsitz, O.; Nasri, F.; Lui, L.M.; Gill, H.; Phan, L.; Chen-Li, D.; Iacobucci, M.; Ho, R.; Majeed, A. Impact of COVID-19 pandemic on mental health in the general population: A systematic review. J. Affect. Disord. 2020, 277, 55-64. [CrossRef]

11. Conway, L.G., III; Woodard, S.R.; Zubrod, A. Social Psychological Measurements of COVID-19: Coronavirus Perceived Threat, Government Response, Impacts, and Experiences Questionnaires. 2020. Available online: https://psyarxiv.com/z2x9a/downloa d? format=pdf (accessed on 15 February 2021).

12. Oosterhoff, B.; Palmer, C.A.; Wilson, J.; Shook, N. Adolescents' motivations to engage in social distancing during the COVID-19 pandemic: Associations with mental and social health. J. Adolesc. Health 2020, 67, 179-185. [CrossRef]

13. Ahmad, M.; Iram, K.; Jabeen, G. Perception-based influence factors of intention to adopt COVID-19 epidemic prevention in China. Environ. Res. 2020, 190, 109995. [CrossRef]

14. Chen, X.; Chen, H. Differences in preventive behaviors of COVID-19 between urban and rural residents: Lessons learned from a cross-sectional study in China. Int. J. Environ. Res. Public Health 2020, 17, 4437. [CrossRef] [PubMed]

15. Siegrist, M.; Luchsinger, L.; Bearth, A. The Impact of Trust and Risk Perception on the Acceptance of Measures to Reduce COVID-19 Cases. Risk Anal. 2021, 0, 1-14.

16. Montaño, D.E.; Kasprzyk, D. Theory of reasoned action, theory of planned behavior, and the integrated behavioral model. Health Behav. Theory Res. Pract. 2015, 70, 231. 
17. Armitage, C.J.; Conner, M. Efficacy of the theory of planned behaviour: A meta-analytic review. Br. J. Soc. Psychol. 2001, 40, 471-499. [CrossRef]

18. Bish, A.; Michie, S. Demographic and attitudinal determinants of protective behaviours during a pandemic: A review. Br. J. Health Psychol. 2010, 15, 797-824. [CrossRef] [PubMed]

19. Cheng, C.; Ng, A.K. Psychosocial factors predicting SARS-preventive behaviors in four major SARS-affected regions. J. Appl. Soc. Psychol. 2006, 36, 222-247. [CrossRef]

20. Kassem, N.O.; Lee, J.W. Understanding soft drink consumption among male adolescents using the theory of planned behavior. J. Behav. Med. 2004, 27, 273-296. [CrossRef]

21. Kassem, N.O.; Lee, J.W.; Modeste, N.N.; Johnston, P.K. Understanding soft drink consumption among female adolescents using the Theory of Planned Behavior. Health Educ. Res. 2003, 18, 278-291. [CrossRef]

22. Kirk, T.N.; Haegele, J.A. Theory of planned behavior in research examining physical activity factors among individuals with disabilities: A review. Adapt. Phys. Act. Q. 2019, 36, 164-182. [CrossRef] [PubMed]

23. Montanaro, E.A.; Kershaw, T.S.; Bryan, A.D. Dismantling the theory of planned behavior: Evaluating the relative effectiveness of attempts to uniquely change attitudes, norms, and perceived behavioral control. J. Behav. Med. 2018, 41, 757-770. [CrossRef]

24. Shi, J.; Kim, H.K. Integrating risk perception attitude framework and the theory of planned behavior to predict mental health promotion behaviors among young adults. Health Commun. 2019, 35, 597-606. [CrossRef]

25. Zhang, N.; Campo, S.; Yang, J.; Janz, K.F.; Snetselaar, L.G.; Eckler, P. Effects of social support about physical activity on social networking sites: Applying the theory of planned behavior. Health Commun. 2015, 30, 1277-1285. [CrossRef] [PubMed]

26. Ajzen, I.; Et Fisbein, M. Understanding Attitudes and Predicting Social Behavior; Prentice Hall: Englewood Cliffs, NY, USA, 1980.

27. Ajzen, I. The theory of planned behavior. Organ. Behav. Hum. Decis. Process. 1991, 50, 179-211. [CrossRef]

28. Ajzen, I. Perceived behavioral control, self-efficacy, locus of control, and the theory of planned behavior 1. J. Appl. Soc. Psychol. 2002, 32, 665-683. [CrossRef]

29. Ajzen, I. The theory of planned behaviour: Reactions and reflections. Psychol. Health 2011, 26, 1113-1127. [CrossRef] [PubMed]

30. Ajzen, I. The theory of planned behavior: Frequently asked questions. Hum. Behav. Emerg. Technol. 2020, 2, 314-324. [CrossRef]

31. McEachan, R.R.C.; Conner, M.; Taylor, N.J.; Lawton, R.J. Prospective prediction of health-related behaviours with the theory of planned behaviour: A meta-analysis. Health Psychol. Rev. 2011, 5, 97-144. [CrossRef]

32. Barile, J.P.; Guerin, R.J.; Fisher, K.A.; Tian, L.H.; Okun, A.H.; Vanden Esschert, K.L.; Jeffers, A.; Gurbaxani, B.M.; Thompson, W.W.; Prue, C.E. Theory-based Behavioral Predictors of Self-reported Use of Face Coverings in Public Settings during the COVID-19 Pandemic in the United States. Ann. Behav. Med. 2021, 55, 82-88. [CrossRef] [PubMed]

33. Das, A.K.; Abdul Kader Jilani, M.M.; Uddin, M.S.; Uddin, M.A.; Ghosh, A.K. Fighting ahead: Adoption of social distancing in COVID-19 outbreak through the lens of theory of planned behavior. J. Hum. Behav. Soc. Environ. 2020, 31, 373-393. [CrossRef]

34. Ashraf, M.A.; Joarder, M.H.R.; Ratan, S.R.A. Consumers' anti-consumption behavior toward organic food purchase: An analysis using SEM. Br. Food J. 2019, 121, 104-122. [CrossRef]

35. George, J.F. Influences on the intent to make Internet purchases. Internet Res. 2002, 12, 165-180. [CrossRef]

36. Bae, S.Y.; Chang, P.-J. The effect of coronavirus disease-19 (COVID-19) risk perception on behavioural intention towards 'untact'tourism in South Korea during the first wave of the pandemic (March 2020). Curr. Issues Tour. 2021, 24, 1017-1035. [CrossRef]

37. Kline, R.B. Principles and Practice of Structural Equation Modeling; Guilford publications: New York, NY, USA, 2015.

38. Ursachi, G.; Horodnic, I.A.; Zait, A. How reliable are measurement scales? External factors with indirect influence on reliability estimators. Procedia Econ. Financ. 2015, 20, 679-686. [CrossRef]

39. Hair, J.F. Multivariate Data Analysis; Prentice Hall: Upper Saddle River, NJ, USA, 2009.

40. Latkin, C.A.; Dayton, L.; Yi, G.; Konstantopoulos, A.; Boodram, B. Trust in a COVID-19 vaccine in the US: A social-ecological perspective. Soc. Sci. Med. 2021, 270, 113684. [CrossRef]

41. Lee, Y.; Li, J.Y.Q. The role of communication transparency and organizational trust in publics' perceptions, attitudes and social distancing behaviour: A case study of the COVID-19 outbreak. J. Contingencies Crisis Manag. 2021, 1-17. [CrossRef]

42. Masser, B.M.; Hyde, M.K.; Ferguson, E. Exploring predictors of Australian community members' blood donation intentions and blood donation-related behavior during the COVID-19 pandemic. Transfusion 2020, 60, 2907-2917. [CrossRef]

43. Kim, H.K.; Tandoc, E.C., Jr. Wear or Not to Wear a Mask? Recommendation Inconsistency, Government Trust and the Adoption of Protection Behaviors in Cross-Lagged TPB Models. Health Commun. 2021, 1-9. [CrossRef]

44. West, R.; Michie, S.; Rubin, G.J.; Amlôt, R. Applying principles of behaviour change to reduce SARS-CoV-2 transmission. Nat. Hum. Behav. 2020, 4, 451-459. [CrossRef]

45. Hameleers, M.; van der Meer, T.G.; Brosius, A. Feeling "disinformed" lowers compliance with COVID-19 guidelines: Evidence from the US, UK, Netherlands and Germany. Harv. Kennedy School Misinformation Rev. 2020, 1. [CrossRef]

46. World Health Organization. Risk Communication and Community Engagement Readiness and Response to Coronavirus Disease (COVID-19): Interim Guidance, 19 March 2020; World Health Organization: Geneva, Switzerland, 2020.

47. Dryhurst, S.; Schneider, C.R.; Kerr, J.; Freeman, A.L.; Recchia, G.; Van Der Bles, A.M.; Spiegelhalter, D.; van der Linden, S. Risk perceptions of COVID-19 around the world. J. Risk Res. 2020, 23, 994-1006. [CrossRef]

48. Malecki, K.; Keating, J.A.; Safdar, N. Crisis communication and public perception of COVID-19 risk in the era of social media. Clin. Infect. Dis. 2021, 72, 697-702. [CrossRef] [PubMed] 
49. Zhang, L.; Li, H.; Chen, K. Effective risk communication for public health emergency: Reflection on the COVID-19 (2019-nCoV) outbreak in Wuhan, China. Healthcare 2020, 8, 64. [CrossRef] [PubMed]

50. University College London. Understanding the Psychological and Social Impact of the Pandemic. Available online: https: / / www.covidsocialstudy.org/ (accessed on 8 March 2021). 